\title{
PERFORATION OF DUPLICATED BOWEL IN CHILDREN
}

\author{
BY \\ JOAN RICHARDS, J. F. E. GILLAM and J. H. THOMAS \\ From the West Wales Hospital Group, Carmarthen
}

(RECEIVED FOR PUBLICATION JUNE 23, 1961)

Duplication of the bowel in children is becoming increasingly recognized as a cause of abdominal pain, obstruction and haemorrhage, but few instances have been published where perforation has occurred. The purpose of this paper is to describe three such cases.

\section{Case Reports}

Case 1. A male, who had melaena at $3 \frac{1}{2}$ months and again a fortnight later, was admitted to hospital on December 26, 1958, when 14 months old. He was shocked with a vague mass across the lower abdomen. On the following day, after a blood transfusion, laparotomy was carried out and perforation of the ileum was closed. Penetration of rectus sheath was present. Occult blood remained positive.

A second operation was performed on March 11, 1959. Meckel's diverticulum six inches distal to previous perforation was removed. This showed superficial ulceration, but no ectopic gastric mucosa was found. Occult blood became negative, but melaena recurred on April 24. (Haemoglobin was $48 \%$ with abdominal distension.)

On May 1, 1959, a third operation was done, and duplicated bowel with its attached ileum was removed and end-to-end anastomosis carried out. Enterogenous cyst was seen about four inches above the duplication. Convalescence was uneventful.

The specimen was 30 inches long and contained another ulcer at the point of perforation. No gastric mucosa was found on section. The ulcer was considered to be pyogenic. Frequent colicky abdominal pain persisted, but no further bleeding occurred.

A fourth operation was carried out on July 13, 1960, when enterogenous cyst was removed without opening the ileum or interfering with its blood supply. No further abnormality of the bowel was discovered. He was symptom-free at follow-up.

Section showed tall, columnar epithelium, muscularis mucosa and circular and longitudinal muscle coats.

Case 2. A male had melaena at $\mathbf{1 0}$ months followed by a hypochromic anaemia (haemoglobin $54-66 \%$ ). When he was $2 \frac{1}{2}$ years of age he experienced abdominal pain with vomiting and constipation for two days.

On November 5, 1960, at 3 years of age, he was admitted with four days' history of abdominal pain, vomiting and melaena. Temperature was $100^{\circ} \mathrm{F}$. $\mathrm{He}$ was dehydrated with a mass across the lower abdomen. There was darkish discoloration of the overlying skin. Haemoglobin was $50 \%$.

On November 6, after a blood transfusion, he was submitted to operation. Perforation of the lower ileum was closed. Black faecal matter had penetrated through into the rectus sheath.

On November 8, severe melaena recurred. Haemoglobin was $44 \%$ and there was abdominal distension.

A second operation was performed on November 10, when a duplicated ileum was removed. It lay entirely within the two layers of the mesentery and shared its blood supply from the inferior mesenteric artery with the normal ileum. It was connected to the ileum at its proximal end about two feet from the ileocaecal valve. This area, measuring two inches and containing the perforation, was resected, and an end-to-end anastomosis was performed. Convalescence was uneventful.

Occult blood was negative at follow-up on April 3, 1961; haemoglobin was $75 \%$.

The specimen was 11 inches long and about three times the diameter of the normal ileum.

Section showed a chronic peptic ulcer of the ileum near the communication.

No gastric mucosa was found in the duplication.

Case 3. A female aged 11 weeks was admitted on May 27, 1960, with melaena. There was a history of occasional vomiting from the age of 3 weeks. Haemoglobin was $64 \%$; with iron medication it rose to $80 \%$. Occult blood remained positive. Barium meal and barium enema were normal.

She was discharged on June 29. On August 2, she was readmitted with recurrence of vomiting. Haemoglobin was $44 \%$. On August 6, she suddenly collapsed and died, and at autopsy perforation in a duplication of stomach was found.

\section{Discussion}

Duplication of the entire colon is not too rare, and occasionally as much as two-thirds of the small intestine may be involved (Jewett, 1958). Morrison (1958) records duplicated cysts of the mediastinum.

Symptoms usually develop within the first three years, but symptomless duplications have been recognized in adults (Moore and Battersby, 1952). 
Most authorities favour the vacuolation theory and believe that enterogenous cysts and duplications are different stages of the same anomaly.

Melaena is common and recurrent colicky abdominal pain with vomiting is often present. Obstruction from distension is usually limited to the duodenum, although Williams (1959) records this complication in the ileocaecal region.

Other manifestations are rare. Elwood (1959) describes extension of a duplicated jejunum into the thorax, and Lynch (1960) reports a haemorrhagic umbilical discharge from a duplicated stomach. Stagg and Lynn (1958), recording a case of perforation, stated that they could find only four similar instances in the literature.

The duplication is usually lined with intestinal mucosa, but ectopic gastric mucosa may be found (Gross, 1953). Ulceration may occur in the normal bowel at the site of communication, or in the duplication itself. The more distal the duplication, the more likely is ulceration to develop (Jewett, 1958).

Diagnosis is difficult as barium studies are often valueless, but plain radiographs may show dilated coils of the duplication.

Surgery, although essential, is hazardous because of the critical condition of the child. The most that can usually be achieved at the first operation is closure of the perforation and assessment of the extent of the duplication. This was the procedure in both our cases and in that of Bohn (1956). Stagg and Lynn (1958) drained an abdominal abscess which resulted in a faecal fistula, before removing a duplication four months later.

Usually the duplication and the normal ileum are removed together and continuity established by end-to-end anastomosis. We have not found an instance where separation, as in our second case, was successful. If the duplication is too extensive the upper end can be anastomosed to the stomach or duodenum (Jewett, 1958).

\section{Summary}

Three cases of perforation due to duplication of the bowel are described.

The relevant literature is briefly reviewed.

\section{REFERENCES}

Bohn, C. L. S (1956) Duplication of ileum. Duplication of the intestinal tract in a child with intestinal perforation treated by intestinal resection. Acta chir. scand., 111, 294

Elwood J. S. (1959). Mediastinal duplication of the gut. Arch. Dis. Childh., 34, 474.

Gross, R. E. (1953). The Surgery of Infancy and Childhood, pp. 474-9. Saunders, Philadelohia.

Jewett, T. C., Jr. (1958). Duplication of the entire small intestine with massive melena. Ann. Surg., 147, 239.

Lynch, G. (1960). Intestinal duplication. J. Irish med. Ass., 46, 143.

Moore, T. C. and Battersby, J. S. (1952). Congenital duplications of the small intestine. Report of 11 cases. Surg. Gynec. of the small intestine. Report of 11 cases. Surg. Gynec.

Morrison, I. M. (1958). Tumours and cysts of the mediastinum. Thorax, 13, 294.

Stagg, P. A. and Lynn, H. B. (1958). Perforated duplication of ileum. Amer. Surg., 24, 415.

Williams, J. A. (1959). Intestinal obstruction in a case of duplication of the terminal ileum. Arch. Dis. Childh., 34, 480. 